\title{
Mitral Valve Stenosis
}

National Cancer Institute

\section{Source}

National Cancer Institute. Mitral Valve Stenosis. NCI Thesaurus. Code C50654.

Narrowing of the left atrioventricular mitral orifice. 